\title{
EFEITO DO TIPO DE CORTE E SANIFICANTES NO AMACIAMENTO DE PEQUI (Caryocar brasiliense CAMB.) MINIMAMENTE PROCESSADO ${ }^{1}$
}

\author{
Effect of the cut type and sanitizers on the softening of fresh cut \\ pequi fruit (Caryocar brasiliense Camb.)
}

\author{
Luiz José Rodrigues², Eduardo Valério de Barros Vilas Boas ${ }^{3}$, Roberta Hilsdorf Piccoli, \\ Nélio Ranieli Ferreira de Paula², Daniella Moreira Pinto², Brígida Monteiro Vilas Boas ${ }^{5}$
}

\begin{abstract}
RESUMO
Frutos e hortaliças minimamente processados devem apresentar atributos de conveniência e qualidade do produto fresco. Com o presente trabalho, objetivou-se avaliar a influência dos sanificantes hipoclorito de sódio ( $\mathrm{NaClO}) 50 \mathrm{ppm}$ e $100 \mathrm{ppm}$ e peróxido de hidrogênio $\left(\mathrm{H}_{2} \mathrm{O}_{2}\right) 4 \%$ e $6 \%$, sobre os processos envolvidos no amaciamento de pequi (Caryocar brasiliense Camb.) minimamente processado submetido a dois tipos de processamento: "caroço fatiado" e "caroço inteiro" e armazenado a $6 \pm 1{ }^{\circ} \mathrm{Ce} 90 \%$ a 95\% UR, durante 15 dias. A cada três dias foram avaliados: perda de massa, firmeza, pectina total, pectina solúvel, atividade de pectinametilesterase (PME) e atividade de poligalacturonase (PG). O pequi minimamente processado apresentou perda de massa e decréscimo de firmeza ao longo do período de armazenamento, concomitante ao aumento da atividade da enzima poligalacturonase, bem como solubilização de substâncias pécticas. Não foi verificada atividade de PME no pequi minimamente processado avaliado. Os caroços fatiados apresentaram maior teor de pectina solúvel, do $3^{\circ}$ ao $6^{\circ}$ dia e atividade da enzima poligalacturonase, do $3^{\circ}$ ao $12^{\circ}$ dia de armazenamento, em relação aos caroços inteiros. A sanificação com $\mathrm{NaClO} 50$ ppm e 100 ppm, $\mathrm{H}_{2} \mathrm{O}_{2} 4 \%$ e $6 \%$ determinou maior solubilização péctica em pequis minimamente processados, ao longo do armazenamento, não sendo observada influência dos sanificantes sobre as variáveis firmeza, perda de massa e atividade de poligalacturonase.
\end{abstract}

Termos para indexação: Caryocar brasiliense, processamento mínimo, refrigeração, fruto nativo.

\begin{abstract}
Fresh cut fruits and vegetables should present convenience and quality features of the fresh produce. The present work aimed to evaluate the influence of the sanitizers $50 \mathrm{ppm}$ and $100 \mathrm{ppm}$ sodium hypochloride $(\mathrm{NaClO})$ and $4 \%$ and $6 \%$ hydrogen peroxide $\left(\mathrm{H}_{2} \mathrm{O}_{2}\right)$ on the involved processes in the softening of fresh cut pequi fruit (Caryocar brasiliense Camb.) submitted to two types of processing: "sliced stone" and "whole stone" stored at $6 \pm 1{ }^{\circ} \mathrm{C}$ and $90 \%$ to $95 \%$ of RH during 15 days. Every three the days mass loss, firmness, total pectin, soluble pectin, pectinmethylesterase activity (PME) and polygalacturonase activity (PG) were evaluated. The fresh cut pequi fruit presented mass loss, firmness decrease along the period of storage, concomitant to the increase of the activity of the enzyme polygalacturonase, as well as the solubilization of substances pectics. Activity of PME was not detected in fresh cut pequi fruit evaluated. The sliced stone showed, higher content of soluble pectins, from $3^{\text {rd }}$ to $6^{\text {th }}$ day and activity of the enzyme polygalacturonase, of $3^{\text {rd }}$ to $12^{\text {th }}$ day of storage, in relation to the whole stones. The sanification with $\mathrm{NaClO} 50 \mathrm{ppm}$ and $100 \mathrm{ppm}$, $\mathrm{H}_{2} \mathrm{O}_{2} 4 \%$ and $6 \%$ presented greater solubilization of pectic substances in fresh cut pequi fruit, during the storage, but it did not influence of the sanitizers on the variable firmness, loss of mass and activity of polygalacturonase.
\end{abstract}

Index terms: Cayocar brasiliense, fresh-cut, refrigeration, native fruit.

(Recebido em 20 de outubro de 2005 e aprovado em 7 de agosto de 2006)

\section{INTRODUÇÃO}

Produtos minimamente processados são definidos como qualquer fruta ou hortaliça, ou qualquer combinação delas, que foi alterada fisicamente a partir de sua forma original, embora mantenha o seu estado fresco. Independente do produto, ele é selecionado, lavado, descascado e cortado num produto $100 \%$ aproveitável que, posteriormente, é embalado ou pré-embalado com o intuito de oferecer aos consumidores frescor, conveniência e qualidade nutricional (IFPA, 2005).

O pequi (Caryocar brasiliense Camb.) é um fruto que reúne vários atributos sensoriais apreciados pelos consumidores, como cor, aroma, textura e aparência, além

\footnotetext{
${ }^{1}$ Parte integrante da dissertação do primeiro autor.

${ }^{2}$ Mestre em Ciência dos Alimentos - Universidade Federal de Lavras/UFLA - Cx. P. 3037 - 37200-000 - Lavras, MG - rodrigues.lui3@uol.com.br; nelioraniel@yahoo.com.br; daniella25@bol.com.br

${ }^{3}$ Pós-Doutor, Professor Adjunto no Departamento de Ciência dos Alimentos/DCA - Universidade Federal de Lavras/UFLA - Cx. P. 3037 - $37200-000$ Lavras, MG - evbvboas@ufla.br

${ }^{4}$ Doutora, Professora Adjunta no Departamento de Ciência dos Alimentos/DCA - Universidade Federal de Lavras/UFLA - Cx. P. 3037 - $37200-000$ Lavras, MG - rvalle@ufla.br

${ }_{5}^{5}$ Doutora em Ciência dos Alimentos - Universidade Federal de Lavras/UFLA - Cx. P. 3037 - 37200-000 - Lavras, MG - bmvboas@hotmail.com
} 
de apresentar teores nutricionais significantes, o que pode favorecer o seu potencial de utilização. O fruto é altamente calórico, com teor de proteínas elevado em relação aos demais frutos encontrados no mercado, além de ser rico em vitamina $A$, na forma de $\beta$-caroteno, e ser altamente oleaginoso (VILAS-BOAS, 2004).

Contudo, o pequi apresenta o mesocarpo interno, que é a porção comestível, aderido ao endocarpo espinhoso. Parte do endocarpo espinhoso chega até mesmo a se confundir, morfologicamente, com o mesocarpo interno (VILAS-BOAS, 2004). Assim, essa inconveniência pode constituir-se em entrave no seu consumo.

Desse modo, o processamento mínimo do pequi pode propiciar um aumento na conveniência do fruto, além de uma alternativa na agregação de valores, contribuindo para a sua expansão na culinária brasileira. $\mathrm{O}$ aumento no grau de conveniência do pequi poderia ser efetivado com sua comercialização já descascado e ou na forma de "fatias", em embalagens com o produto pronto para ir para panela. Por outro lado, o descascamento e o corte das frutas minimamente processadas promovem um aumento no seu metabolismo, em tempo relativamente curto, com conseqüente aumento na taxa respiratória e produção de etileno. Outra conseqüência do ferimento são as alterações na textura e o aumento da perda de água (BRECHT, 1995).

O amaciamento é uma das mais importantes modificações normalmente observadas durante o amadurecimento de frutos (HUBER, 1983). A diminuição da firmeza pode ser atribuída à perda excessiva de água por transpiração, o que ocorre no armazenamento em atmosfera com baixa umidade relativa. A perda de firmeza, no entanto, é mais freqüentemente atribuída à decomposição enzimática da lamela média e da parede celular (FISCHER et al., 1994). Um grande número de enzimas tem participação na degradação das substâncias pécticas, tais como pectinametilesterase, poligalacturonase, â-galactosidase, celulase, entre outras. As mais importantes e objeto de maiores estudos são as pectinametilesterases (PME) e as poligalacturonases (PG) (BARRET \& GONZALEZ, 1994).

Outro fator que pode ser considerado limitante, do ponto de vista da sua qualidade, é que os pequis são normalmente coletados do chão (VILAS-BOAS, 2004). A maioria dos frutos, quando maduros, se desprendem da "planta-mãe" caindo ao chão e entrando em contato direto com o solo, tornando-se veículo de contaminação e fonte de microrganismos patogênicos que podem se instalar na sua superfície.

Com o presente trabalho, buscou-se verificar a influência dos tipos de corte (caroço fatiado e caroço inteiro) e os sanificantes hipoclorito de sódio $(\mathrm{NaClO})$ e peróxido de hidrogênio $\left(\mathrm{H}_{2} \mathrm{O}_{2}\right)$, em diferentes concentrações, sobre o amaciamento de pequi minimamente processado, armazenado a $6^{\circ} \mathrm{C}$, durante 15 dias.

\section{MATERIAL E MÉTODOS}

Foram utilizados pequis (Caryocar brasiliense) provenientes da cidade de Itumirim, situada no Sul do Estado de Minas Gerais. Os frutos foram colhidos pela manhã, ao acaso, do chão, ou mesmo, quando ainda unidos à planta-mãe, porém, apresentavam rachaduras no epicarpo e mesocarpo externo, ficando à mostra o mesocarpo interno. Em seguida, procedeu-se a seleção quanto à aparência, ausência de injúrias e podridões, ausência de cheiro característico de deterioração e quanto ao grau de maturação (polpa com coloração amarelada).

Em seguida, foram levados para o Laboratório de Pós-Colheita de Frutas e Hortaliças do Departamento de Ciência dos Alimentos (DCA) da Universidade Federal de Lavras (UFLA). No laboratório, os frutos foram novamente selecionados, procurando tornar o lote ainda mais uniforme quanto ao grau de maturação e ausência de danos mecânicos ou podridões.

Os pequis tiveram as superfícies lavadas com detergente neutro para remoção de sujidades grosseiras provenientes do campo. Posteriormente, foram enxagüados em água corrente até a completa remoção do detergente.

Após a lavagem, os frutos foram armazenados imediatamente em câmara fria a $12 \pm 1^{\circ} \mathrm{C}$ e umidade relativa (UR) entre $90 \%$ a $95 \%$, por aproximadamente 15 horas.

Após este período, os pequis foram levados para a Sala de Processamento Mínimo, sendo descascados manualmente com o auxílio de facas afiadas. Em seguida, os caroços foram, ou não, fatiados no sentido longitudinal utilizando-se um fatiador manual de aço inoxidável, tomando-se o cuidado de retirar apenas o mesocarpo interno, evitando o endocarpo espinhoso, de modo que as fatias se apresentaram com aproximadamente $0,2 \mathrm{~cm}$ de espessura.

Os caroços "inteiros" e os "fatiados" foram imersos nas soluções que correspondiam aos tratamentos por 5 minutos; controle: imersão em água pura a $8^{\circ} \mathrm{C}$, hipoclorito de sódio $(\mathrm{NaClO}) 50$ e 100 ppm a $8^{\circ} \mathrm{C}$, peróxido de hidrogênio $\left(\mathrm{H}_{2} \mathrm{O}_{2}\right) 4$ e $6 \%$ à temperatura ambiente $\left(23^{\circ} \mathrm{C}\right)$.

Em todos os tratamentos e no controle verificou-se o pH das soluções. Para o $\mathrm{NaClO} 50$ e 100 ppm, correspondeu a 6,5 e 6,8, respectivamente; já para o $\mathrm{H}_{2} \mathrm{O}_{2}$ $4 \%$ e $6 \%$, os valores de $\mathrm{pH}$ foram de 5,5 e 5,8 , 
respectivamente e o controle (água) apresentou $\mathrm{pH}$ em torno de 6,0 .

Decorrido o tempo de imersão, os frutos minimamente processados foram centrifugados a $750 \mathrm{rpm}$ por 1 minuto, para drenagem do excesso de líquido. Em seguida, dez caroços inteiros e cerca de 100 gramas em fatias foram acondicionados em bandejas plásticas (10/20 $\mathrm{cm}$ ) envoltas por filme de policloreto de vinila (PVC) de $15 \mathrm{~mm}$, flexível e auto-adesível, previamente higienizadas. As embalagens foram armazenadas em câmara fria a $6 \pm 11^{\circ} \mathrm{C}$ e $90 \%$ a $95 \%$ UR, durante um período de 15 dias e as análises realizadas a cada três dias.

As análises realizadas foram: perda de massa (\%), considerando-se a diferença entre a massa inicial do pequi minimamente processado e aquela obtida a cada intervalo de tempo de armazenamento; firmeza $(\mathrm{N})$, determinada somente no pequi minimamente processado na forma do "caroço inteiro" com o auxílio de um texturômetro Stable Micro System modelo TAXT2; pectina total e solúvel (mg de ácido galacturônico.100g de polpa $^{-1}$ ), extraídas de acordo com a técnica descrita por McCready \& McColomb (1952), e seus teores determinados espectrofotometricamente a $520 \mathrm{~nm}$, segundo Bitter \& Muir (1973); pectinametilesterase (PME) ( $\eta$ mol.g $\mathrm{g}^{-1} \cdot$ minuto $\left.^{-1}\right)$, extraída segundo técnica de Buescher \& Furmanski (1978), com modificações de Vilas-Boas (1995) e o doseamento segundo Hultin et al. (1966) e Ratner (1969), com modificações de Vilas-Boas (1995); poligalacturonase (PG) $\left(\eta\right.$ mol.g ${ }^{-1} \cdot$ minuto $\left.^{-1}\right)$, extraída segundo a técnica de Buescher \& Furmanski (1978), com modificações de Vilas-Boas (1995) e o doseamento realizado segundo Markovic et al. (1975), com modificações de Vilas-Boas (1995).

As análises foram conduzidas segundo um delineamento inteiramente casualizado (DIC), em esquema fatorial $2 \times 6 \times 5$, ou seja, 2 tipos de processamento (caroços "fatiados" e "inteiros"), 6 tempos (0h, 3, 6, 9, 12, 15 dias) e 5 tratamentos (controle, $\mathrm{NaClO} 50$ ppm, $\mathrm{NaClO} 100$ ppm, $\mathrm{H}_{2} \mathrm{O}_{2} 4 \%$ e $\mathrm{H}_{2} \mathrm{O}_{2} 6 \%$ ), com 3 repetições. A análise estatística foi realizada com o auxílio do programa SISVAR. As respostas das variáveis avaliadas foram submetidas à análise de variância aplicada ao DIC, sendo que os tratamentos analisados em função do tempo foram aleatorizados conforme o esquema de parcela subdividida. As médias de tratamentos, quando significativas foram comparadas pelo teste de Tukey a $1 \%$ e $5 \%$ de probabilidade. Já os modelos de regressões polinomiais foram selecionados com base na significância do teste de $\mathrm{F}$ de cada modelo testado e também pelo coeficiente de determinação.

\section{RESULTADOS E DISCUSSÃO}

$\mathrm{O}$ caroço fatiado do pequi apresentou perda de massa de $1,13 \%$, ao passo que, o caroço inteiro a perda foi de $1,07 \%$.

Observou-se um incremento linear na perda de massa ao longo do período de armazenamento, sendo esse aumento mais pronunciado no $15^{\circ}$ dia de armazenamento, atingindo 2,16\% (Figura 1). Não houve efeito dos outros fatores sobre esta variável.

De acordo com Carvalho (1999), em geral, perdas na ordem de $5 \%$ a $10 \%$ são suficientes para causarem um marcante declínio na qualidade em frutos, promovendo perdas na aparência, como o enrugamento do produto. Esses valores de perda de massa do pequi minimamente processado podem ser atribuídos ao tipo de filme polimérico utilizado (PVC 15mm), não se constituindo barreira eficiente à perda de água.

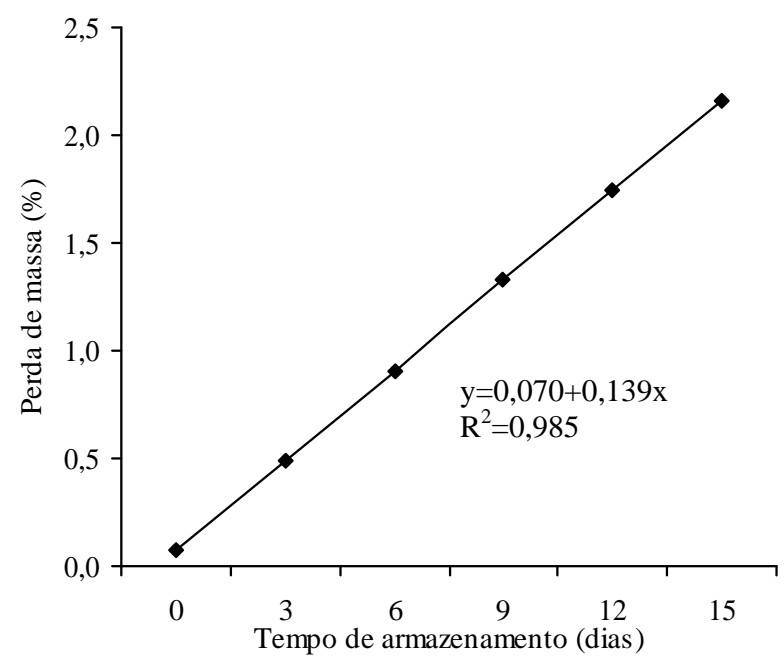

Figura 1 - Perda de massa em pequi minimamente processado submetido a tratamentos com $\mathrm{NaClO}$ e $\mathrm{H}_{2} \mathrm{O}_{2}$, em diferentes concentrações, armazenado a $6^{\circ} \mathrm{C}$ por 15 dias.

A firmeza foi afetada significativamente apenas pelo fator tempo de armazenamento, não tendo sido influenciada pelo sanificante utilizado.

A firmeza foi determinada somente nos frutos inteiros devido à dificuldade de se avaliar essa variável nos pequis fatiados. Durante o período de armazenamento observou-se um decréscimo linear na firmeza no pequi minimamente processado, de 4,24 a 2,48N imediatamente após o processamento e aos 15 dias de armazenamento a $6^{\circ} \mathrm{C}$ (Figura 2), respectivamente. 


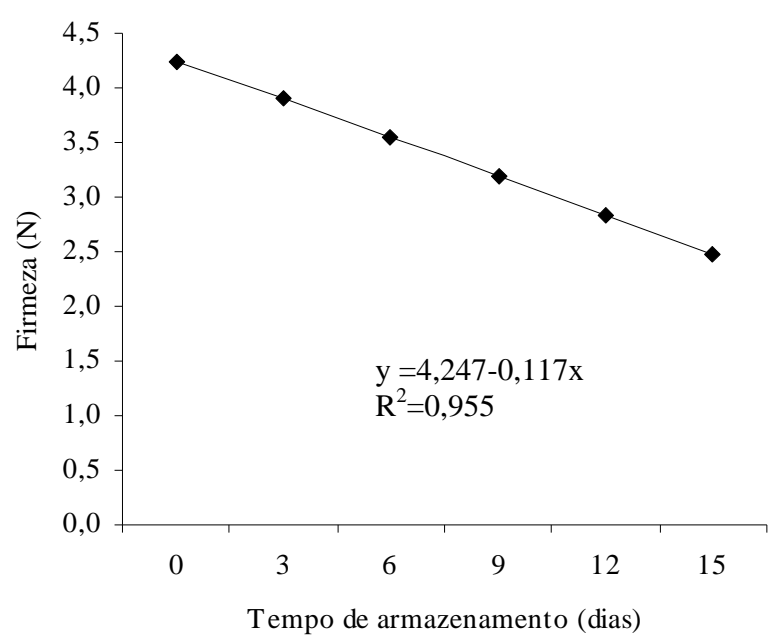

Figura 2 - Firmeza em pequi minimamente processado submetido a tratamentos com $\mathrm{NaClO}$ e $\mathrm{H}_{2} \mathrm{O}_{2}$, em diferentes concentrações, armazenado a $6^{\circ} \mathrm{C}$ por 15 dias.

A diminuição da firmeza pode estar relacionada, principalmente, com a perda de integridade da parede celular, relacionado com a sua hidrólise enzimática, devido à ação de enzimas pectinolíticas, como a poligalacturonase $\mathrm{e}$ pectinametilesterase, bem como celulases e $\beta$-galactosidases, uma vez que as células, danificadas por ocasião do corte, liberam essas enzimas, difundindo-se para o interior dos tecidos, promovendo intensa solubilização das pectinas. Essas enzimas degradam a estrutura celular que é responsável pela firmeza do tecido vegetal em frutas e hortaliças (CHITARRA, 2000).

As variáveis pectina total e solúvel foram influenciadas pelo fator isolado sanificante e pela interação corte e tempo de armazenamento. Os pequis tratados com $\mathrm{NaClO} 100$ ppm, $\mathrm{H}_{2} \mathrm{O}_{2} 4 \%$ e $6 \%$ apresentaram teores de pectina total semelhantes entre si, superiores aos dos caroços controle e sanificados com $\mathrm{NaClO} 50$ ppm, que também não diferiram entre si (Tabela 1).

Os valores de pectina total dos caroços fatiados e inteiros não diferiram até o $3^{\circ}$ dia, porém, ao $6^{\circ}$ dia de armazenamento, os caroços fatiados apresentaram-se com menores teores em comparação ao inteiro, seguindo esse comportamento até o $15^{\circ}$ dia. Os teores de pectina total nos caroços fatiados aumentaram até o $6^{\circ}$ dia de armazenamento, decrescendo até o final do armazenamento. Modificações semelhantes foram observadas nos caroços inteiros do pequi, porém, a redução iniciou-se no $6^{\circ}$ dia, seguindo até o $15^{\circ}$ dia de armazenamento (Figura 3).
Tabela 1 - Pectina total em pequi minimamente processado submetido a diferentes sanificantes e armazenado a $6^{\circ} \mathrm{C}$ por 15 dias.

\begin{tabular}{lc}
\hline \multicolumn{1}{c}{ Sanificantes } & $\begin{array}{c}\text { Pectina total } \\
\left.\text { (mg ac. galacturônico.100 } \text { g polpa }^{-1}\right)\end{array}$ \\
\hline Controle & $1850,528 \mathrm{a}$ \\
$\mathrm{NaClO} 50 \mathrm{ppm}$ & $1851,033 \mathrm{a}$ \\
$\mathrm{NaClO} 100 \mathrm{ppm}$ & $1859,922 \mathrm{~b}$ \\
$\mathrm{H}_{2} \mathrm{O}_{2} 4 \%$ & $1861,866 \mathrm{~b}$ \\
$\mathrm{H}_{2} \mathrm{O}_{2} 6 \%$ & $1862,997 \mathrm{~b}$ \\
\hline
\end{tabular}

Médias seguidas da mesma letra não diferem estatisticamente, a $5 \%$ de probabilidade, pelo teste de Scott-Knott.

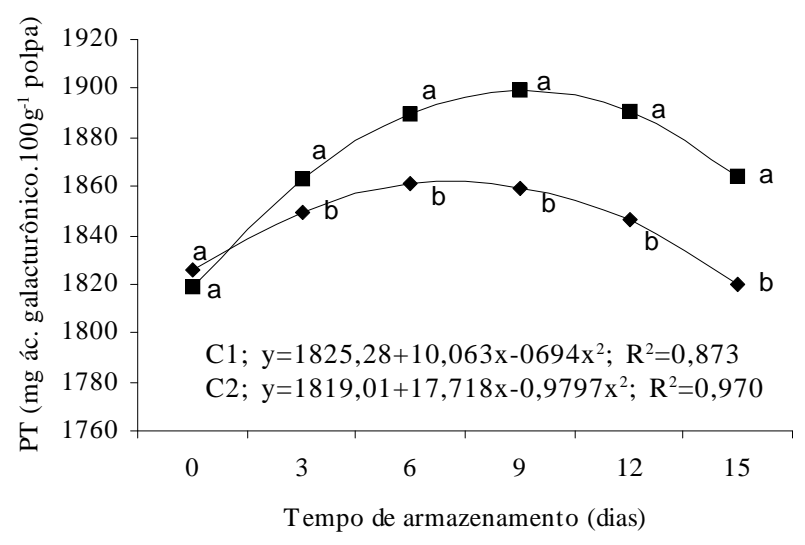

Figura 3 - Pectina total (PT) em pequi minimamente processado submetido a diferentes cortes: $\mathbf{C 1}=$ "fatiado" e $\mathbf{C 2}=$ "inteiro" em tratamentos com $\mathrm{NaClO}$ e $\mathrm{H}_{2} \mathrm{O}_{2}$, em diferentes concentrações, armazenado a $6^{\circ} \mathrm{C}$ por 15 dias. * Médias seguidas da mesma letra entre as equações de regressão representam semelhanças estatísticas entre os cortes, a 5\% de probabilidade, pelo teste de Scott-Knott.

O controle apresentou maiores teores de pectina solúvel em relação aos pequis sanificados, tendo esses apresentado semelhanças estatísticas entre si (Tabela 2).

Observou-se um aumento linear no teor de pectina solúvel dos caroços fatiados e inteiros, no decorrer do armazenamento (Figura 4). O incremento da pectina solúvel com o armazenamento pode ser associado à perda de firmeza no pequi minimamente processado (Figura 2). $\mathrm{O}$ amaciamento é marcado por modificações das substâncias pécticas da parede celular, que vão sendo solubilizadas, 
transformando a pectina insolúvel (protopectina) em pectina solúvel. Esse amolecimento ocorre em razão da diminuição das forças coesivas que mantêm as células unidas decorrentes da decomposição da protopectina pela ação das enzimas poligalacturonase (PG) e pectinametilesterase (PME) (FACHIN, 2003; VILAS-BOAS et al., 2000).

Tabela 2 - Pectina solúvel em pequi minimamente processado submetido a diferentes sanificantes e armazenado a $6^{\circ} \mathrm{C}$ por 15 dias.

\begin{tabular}{lc}
\hline \multicolumn{1}{c}{ Sanificantes } & $\begin{array}{c}\text { Pectina solúvel } \\
\left.\text { (mg ac. galacturônico.100g polpa }{ }^{-1}\right)\end{array}$ \\
\hline Controle & $282,255 \mathrm{~b}$ \\
$\mathrm{NaClO} \mathrm{50} \mathrm{ppm}$ & $275,748 \mathrm{a}$ \\
$\mathrm{NaClO} 100 \mathrm{ppm}$ & $275,154 \mathrm{a}$ \\
$\mathrm{H}_{2} \mathrm{O}_{2} 4 \%$ & $276,801 \mathrm{a}$ \\
$\mathrm{H}_{2} \mathrm{O}_{2} 6 \%$ & $271,399 \mathrm{a}$ \\
\hline
\end{tabular}

Médias seguidas da mesma letra não diferem estatisticamente, a $5 \%$ de probabilidade, pelo teste de Scott-Knott.

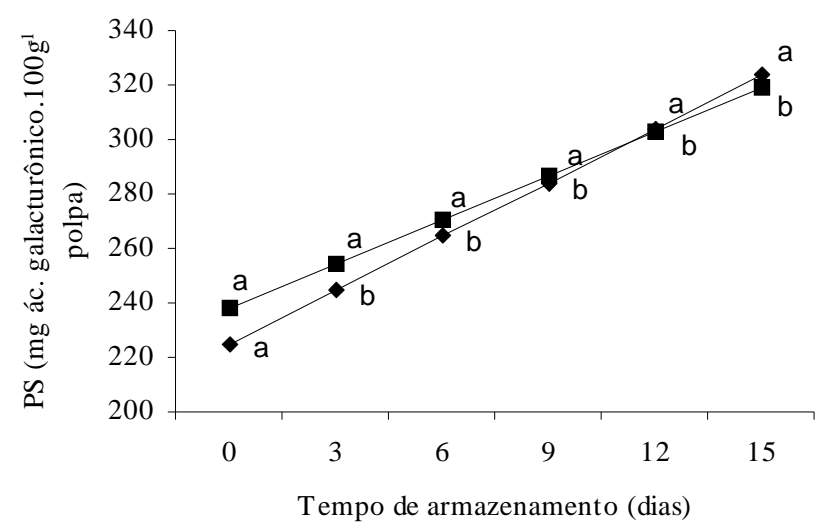

$\longrightarrow \mathrm{C} 1 \rightarrow \mathrm{C} 2$

Figura 4 - Pectina solúvel (PS) em pequi minimamente processado submetido a diferentes cortes: $\mathbf{C 1}=$ "fatiado" e $\mathbf{C 2}=$ "inteiro" em tratamentos com $\mathrm{NaClO}$ e $\mathrm{H}_{2} \mathrm{O}_{2}$, em diferentes concentrações, armazenado a $6^{\circ} \mathrm{C}$ por 15 dias. *Médias seguidas da mesma letra entre as equações de regressão representam semelhanças estatísticas entre os cortes, a $5 \%$ de probabilidade, pelo teste de Scott-Knott.
A atividade da enzima pectinametilesterase (PME) não foi detectada no pequi minimamente processado. Santos et al. (2005) também não observaram atuação dessa enzima em abacaxi minimamente processado, creditando a sua ausência ao estádio de maturação avançado dos frutos, visto que o ápice de ação da enzima ocorre em estádios verdes da maturação. Tal fato possivelmente ocorreu no pequi minimamente processado.

A atividade da enzima poligalacturonase foi afetada significativamente pela interação corte e tempo de armazenamento, não tendo sido afetada pelo fator sanificante. Observou-se incremento linear na atividade da PG nos caroços inteiros, variando de 2,81 a $21,82 \eta \mathrm{mol} . \mathrm{g}^{-1} \cdot \mathrm{min}^{-1}$ e comportamento quadrático nos caroços fatiados, com elevação na atividade até o $12^{\circ}$ dia (1,79 a 21,09 $\left.\eta \mathrm{mol} \cdot \mathrm{g}^{-1} \cdot \mathrm{min}^{-1}\right)$, seguida de estabilização, ou queda (Figura 5).

Os caroços inteiros apresentaram menor atividade de $\mathrm{PG}$ do $3^{\circ}$ ao $12^{\circ}$ dias de armazenamento, e nenhuma diferença foi observada aos 0 e 15 dias.

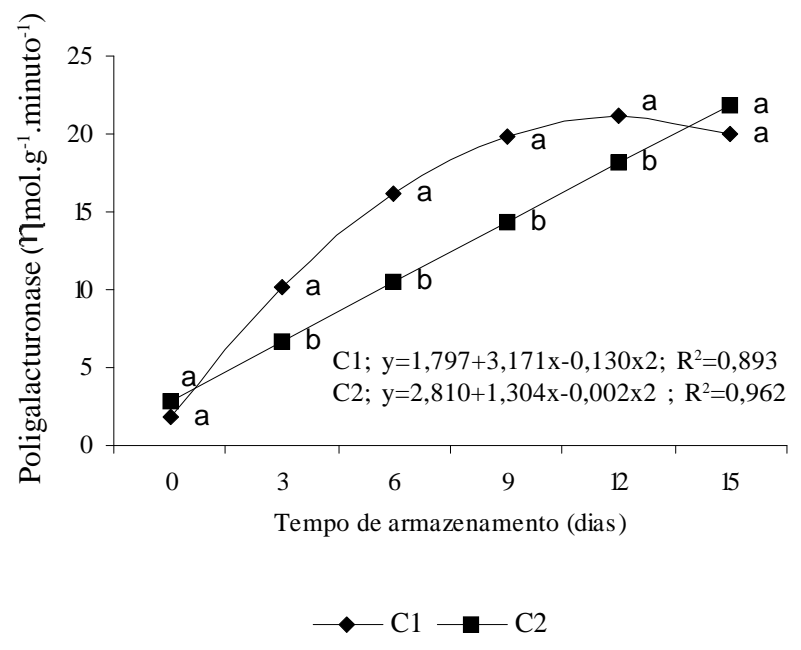

Figura 5 - Poligalacturonase em pequi minimamente processado submetido a diferentes cortes: $\mathbf{C 1}=$ "fatiado" e $\mathbf{C 2}=$ "inteiro" em tratamentos com $\mathrm{NaClO}$ e $\mathrm{H}_{2} \mathrm{O}_{2}$, em diferentes concentrações, armazenado a $6^{\circ} \mathrm{C}$ por 15 dias. *Médias seguidas da mesma letra entre as equações de regressão representam semelhanças estatísticas entre os cortes, a 5\% de probabilidade, pelo teste de Scott-Knott.

O maior índice de pectina solúvel e a perda de firmeza ao longo do armazenamento (Figuras 2 e 4) podem ser relacionados ao incremento da atividade da enzima poligalacturonase, principalmente no pequi fatiado. A maior atividade da PG no caroço do pequi fatiado ocorreu, 
provavelmente, como conseqüência do corte, que induziu a descompartimentalização celular, promovendo o contato entre enzima e substrato. Presume-se que no $15^{\circ}$ dia de armazenamento, esta enzima já tenha atingido o seu pico de atuação no caroço fatiado, devido ao estádio de maturação avançado dos frutos, resultando no decréscimo de sua atividade.

\section{CONCLUSÕES}

$\mathrm{O}$ armazenamento de pequi minimamente processado a $6 \pm 1^{\circ} \mathrm{C}$ e $90-95 \%$ de UR é marcado pelo seu amaciamento, acompanhado pela ascensão da atividade da enzima poligalacturonase e solubilização péctica, bem como aumento na perda de massa.

$\mathrm{O}$ fatiamento dos caroços de pequi determinou maior solubilização péctica, do $3^{\circ}$ ao $6^{\circ}$ dia, e maior atividade da enzima poligalacturonase, do $3^{\circ}$ ao $12^{\circ}$ dia de armazenamento.

As variáveis firmeza, perda de massa e atividade de poligalacturonase não são influenciadas pela sanificação de caroços e fatias de pequi, com $\mathrm{NaClO} 50$ e 100 ppm e $\mathrm{H}_{2} \mathrm{O}_{2} 4$ e $6 \%$.

A sanificação com $\mathrm{NaClO} 50$ e 100 ppm, $\mathrm{H}_{2} \mathrm{O}_{2} 4 \%$ e $6 \%$ determina maior solubilização péctica em pequis minimamente processados, ao longo do armazenamento.

\section{AGRADECIMENTOS}

Os autores agradecem ao $\mathrm{CNPq}$, pelo suporte financeiro e à CAPES, pela bolsa de estudos concedida ao primeiro autor.

\section{REFERÊNCIAS BIBLIOGRÁFICAS}

BARRET, D. M.; GONZALEZ, C. Activity of softening enzymes during cherry maturation. Journal of Food Science, Chicago, v. 59, n. 3, p. 574-577, May/June 1994.

BITTER, T.; MUIR, H. M. A modified uronic acid carbazole reaction. Analytical Biochemistry, New York, v. 4, n. 4, p. 330-334, 1973.

BRECHT, J. K. Physiology of lightly processed fruits and vegetables. Hortscience, Alexandria, v. 30, n. 1, p. 18-22, Feb. 1995.

BUESCHER, R. W.; FURMANSKI, R. J. Role of pectinasterase and polygalacturonase in the formation of woolliness un peaches. Journal of Food Science, Chicago, v. 43, n. 1, p. 264-266, Jan./Feb. 1978.
CARVALHO, H. A. Utilização de atmosfera modificada na conservação pós-colheita de goiaba 'Kumagai'. 1999. 118 p. Tese (Doutorado em Ciência dos Alimentos) Universidade Federal de Lavras, Lavras, 1999.

CHITARRA, M. I. F. Processamento mínimo de frutas e hortaliças. Lavras: UFLA/FAEPE, 2000. 113 p. Apostila.

FACHIN, D. Temperature and pressure inactivation of tomato pectinases: a kinetic study. 2003. $133 \mathrm{f}$. Proefschrift (Doctorats in de Toegepaste Biologische Wetenschappen door) - Katholieke Universiteit Leuven, Lerven, 2003.

FISHER, M.; ARRIGONI, E.; AMADO, R. Changes in pectic substances of apples during development and postharvest ripening: part 2: analysis of the pectin fraction. Carbohidrate Polymers, London, v. 25, n. 6, p. 167-175, 1994.

HUBER, D. J. The role of cell wall hydrolases in fruit softening. Horticultural Review, New York, v. 5, p. 169219, 1983.

HULTIN, H. O.; SUN, B.; BULGER, J. Pectin methyl esterases of the banana: purification and propierties. Journal of Food Science, Chicago, v. 31, n. 3, p. 320-327, May/June 1966.

IFPA. International fresh-cut produce association. Disponível em: <http://www.fresh-cuts.org>. Acesso em: 29 mar. 2005.

MARKOVIC, O.; HEINRICHOVÁ, K.; LENKEY, B. Pectolytic enzymes from banana. Collection Czechoslovak Chemistry Community, London, v. 40, p. 769-774, 1975.

McCREADY, P. M.; McCOMB, E. A. Extraction and determination of total pectic material. Analytical Chemistry, New York, v. 24, n. 12, p. 1586, 1952.

RATNER, A.; GOREN, R.; MONSELINE, S. P. Activity of pectin esterase and cellulase in the abcission zone of citrus leaft explants. Plant Physiology, Rockville, v. 44, n. 12, p. 1717-1723, Dec. 1969.

SANTOS, J. C. B.; VILAS-BOAS, E. V. B.; PRADO, M. E. T.; PINEIRO, A. C. M. Avaliação da qualidade de abacaxi 'Pérola' minimamente processado armazenado sob atmosfera modificada. Ciência e Agrotecnologia, Lavras, v. 29, n. 2, p. 353-361, mar./abr. 2005. 
VILAS-BOAS, E. V. de B. Frutas minimamente processadas: pequi. In: ENCONTRO NACIONAL SOBRE PROCESSAMENTO MINIMO DE FRUTAS E HORTALIÇAS, 3., 2004, Viçosa, MG. Anais... Viçosa: UFV, 2004. p. 122-127.

VILAS BOAS, E. V. de B. Modificações pós-colheita de banana 'Prata' (Musa acuminata x Musa balbisiana grupo AAB) ã-irradiada. 1995. 73 f. Dissertação (Mestrado em
Ciência dos Alimentos) - Universidade Federal de Lavras, Lavras, 1995.

VILAS-BOAS, E. V. B.; CHITARRA, A. B.; MALUF, W. R.; CHITARRA, M. I. F. Modificações texturais de tomates heterozigotos no loco Alcobaça. Pesquisa Agropecuária Brasileira, Brasília, v. 35, n. 7, p. 1447 1453, jul. 2000. 